\title{
ANÁLISES CONTRASTIVAS: ESTABILIDADE, VARIEDADE OU METODOLOGIA?
}

CONTRASTIVE ANALYSES: STABILITY, VARIETY OR METHODOLOGY?

\begin{abstract}
Raquel Meister Ko. Freitag
Professora do Departamento de Letras Vernáculas, do Programa de Pós-Graduação em Letras e do Programa de Pós-Graduação em Educação da Universidade Federal de Sergipe/CNPq. rkofreitag@uol.com.br.
\end{abstract}

\section{Claudia Andrea Rost Snichelotto}

Professora do Curso de Graduação em Letras Português e Espanhol e do Programa de Pós-Graduação em Estudos Linguísticos da Universidade Federal da Fronteira Sul. claudiarost@uffs.edu.br.

RESUMO: Resultados de estudos sociolinguísticos em amostras sincrônicas como a do banco de dados do núcleo VARSUL têm trazido contribuições para a descrição do português brasileiro. A amostra oral de Florianópolis, especificamente, tem subsidiado estudos de fenômenos variáveis, que, contrastados a outras variedades, sugere indícios de variação diatópica. As evidências podem sinalizar para três explicações: (1) reiterar que o rumo da investigação deve ser em direção ao que é igual, não ao diferente, dado que há muito mais estabilidade do que instabilidade no sistema do português brasileiro; (2) corroborar a crença de que no Brasil todos falam português, mas existe julgamento de pertença ou de diferença, que é indiciado pela distribuição de frequências; e (3) demonstrar que as escolhas metodológicas da constituição das amostras orais devem ser pautadas em critérios visando à confiabilidade e à intersubjetividade das análises (BAILEY; TILLERY, 2004), de modo a possibilitar a generalização de resultados. Comparamos resultados de dois fenômenos variáveis no português que foram estudados na amostra do VARSUL de Florianópolis - a expressão da primeira pessoa do plural e a do passado imperfectivo -, com outras variedades, para identificar aspectos metodológicos que permeiam as análises e que devem ser considerados em novas coletas para constituição e ampliação de bancos de dados sociolinguísticos.

PALAVRAS-CHAVE: Bancos de dados sociolinguísticos. Metodologia. Primeira pessoa do plural. Passadoimperfectivo.

ABSTRACT: Achievements of sociolinguistic approaches in synchronic samples as VARSUL data bank have been contribute to Brazilian Portuguese description. Oral sample of Florianopolis has been subside studies of variable phenomena that in contrast with others varieties point diatopic variation evidences. These evidences can suggest three explanations: (1) reinforce that the directions of investigations should be to the same, not to the different, seeing that the Brazilian Portuguese system presents more stability than instability; (2) corroborate the belief that in Brazilian everybody speaks same language but there is an aptness or difference judge, pointed by frequency distribution of linguistic data; and (3) demonstrate that methodological choses of 
constitution oral samples should be ruled by criteria of reability and intersubjeticity and enable the generalization of analysis. We compare results of two variable phenomena that went studied in Florianópolis sample of VARSUL data bank - the expression of plural first person and the imperfective past - with results of others varieties, and we identify methodological aspects that permeate analyses and should be considerate in new data collected for constitution and enlargement of sociolinguistic data banks.

KEYWORDS: Sociolinguistic data bank. Methodology. Plural first person. Imperfetive past.

\section{INTRODUÇÃO'}

O brasileiro acredita que o Brasil é um país monolíngue, onde todos falam o português. Os estudos de base sociolinguística e dialetológica têm tentado desfazer esse mito, com investigações que mostram uma realidade plurilíngue e diversificada. No entanto, cria-se outro mito, o do "Português Brasileiro". Afinal, o que é o "Português Brasileiro"? O GT de Sociolinguística da ANPOLL organizou duas coletâneas de trabalhos desenvolvidos sob a égide de "Português Brasileiro" e a terceira está a caminho (ABRAÇADO; RONCARATI, 2003; 2008). Talvez possamos entender a postulação da diferença face ao português Europeu (Portugal) ou Africano (mas de qual país?), por exemplo. Do ponto de vista gramatical, no que se difere o falar do sulista em relação ao do nordestino? O que diferencia o falar florianopolitano do restante do Brasil?

Resultados de estudos sociolinguísticos em amostras sincrônicas, como a do banco de dados do núcleo VARSUL - Variação Linguística Urbana da Região Sul do Brasil $^{2}$ - trazem contribuições para essa discussão. A amostra oral de Florianópolis, especificamente, tem subsidiado estudos de fenômenos variáveis de natureza morfossintática e semântico-pragmática, que, contrastados a outra variedade, como a de Chapecó, têm apontado indícios de variação regional para:

- quer dizer marcador reparador (DAL MAGO, 2001) - maior recorrência em Chapecó do que em Florianópolis;

- bom e bem marcador de prefaciação (MARTINS, 2003) - inibição de bom e favorecimento de bem na fala de ambas as comunidades;

- variação dos pronomes possessivos de segunda pessoa do singular teu/seu (ARDUIN, 2005) - apenas uma ocorrência de teu/você em Chapecó.

\footnotetext{
${ }^{1}$ Este texto apresenta reflexões metodológicas basilares do projeto interinstitucional de pesquisa Como $o$ brasileiro acha que fala? Estudos contrastivos de variação e identidade no português falado no Brasil, edital CNPq 14/2013 Universal - Faixa C, cujo objetivo é investigação de caráter constrativovariacionista e perceptual, com amostras de comunidades de fala específicas: Chapecó e Florianópolis, em Santa Catarina, na região Sul, e Natal, no Rio Grande do Norte, e Aracaju, em Sergipe, na região nordeste do Brasil.

${ }^{2}$ Detalhes da constituição do VARSUL podem ser conferidos em: <http://www.varsul.org.br>.
} 
- variação no uso das preposições (a/para em) no complemento locativo do verbo ir de movimento (WIEDEMER, 2008) - indícios de mudança em andamento com recuo gradativo da preposição $a$ em Chapecó e Florianópolis.

- marcadores discursivos olha e vê (e suas variações) (ROST SNICHELOTTO, 2009) maior atuação de olha em Chapecó, em oposição a vê, que é mais empregado em Florianópolis.

O contraste de resultados na base do VARSUL/Florianópolis com resultados de estudos em outras variedades, também focando fenômenos de natureza morfossintática e semântico-pragmática, aponta indícios da variação e estabilidade:

- Para marcadores discursivos de base interacional, Freitag (2008) - comparando resultados da amostra de Florianópolis do VARSUL com resultados de uma amostra piloto nos mesmos moldes coletada em Itabaiana/SE - que deu origem ao banco Falares Sergipanos (FREITAG, 2013) - constatou que marcadores discursivos interacionais são suscetíveis ao contexto sociolinguístico, com a identificação de marcadores como pronto, repare, espia etc. em Itabaiana/SE e entendesse, não tem? etc. em Florianópolis/SC.

- Para os conectores E, AÍ, DAÍ e ENTÃO, variantes de realização da função gramatical de sequenciação retroativo-propulsora de informações, Tavares (2008) contrastou resultados referentes à fala de Natal/RN e à fala de Florianópolis/SC quanto à influência das variáveis sociais idade e nível de escolaridade.

Tais resultados podem apontar para três explicações: (1) reiterar que o rumo da investigação deve ser em direção ao que é igual, não ao diferente, dado que, no sistema do português brasileiro, há muito mais estabilidade do que instabilidade; (2) corroborar a crença de que no Brasil todos falam português, todos se entendem, mas todos estabelecem um julgamento de pertença ou de diferença, que é indiciado pela distribuição de frequências; ou (3) demonstrar que as escolhas metodológicas da constituição das amostras orais devem ser pautadas em critérios visando à confiabilidade e à intersubjetividade das análises (BAILEY; TILLERY, 2004), de modo a possibilitar a generalização de resultados, pois enquanto os estudos contrastivos entre a variedade de Florianópolis e de Chapecó compartilham não só do mesmo protocolo de coleta de dados, mas também do mesmo escopo temporal (as amostras foram constituídas à mesma época), os outros estudos, ainda que tentem aplicar os mesmos critérios, são distantes temporalmente em pelo menos uma década.

Propomos, neste texto, uma reflexão acerca dessas possibilidades, tomando por base dois fenômenos variáveis no português que foram estudados na amostra do VARSUL de Florianópolis: a expressão da primeira pessoa do plural e a do passado imperfectivo. O contraste dos resultados obtidos nessa amostra com os resultados obtidos em amostras de outras variedades possibilita a identificação de aspectos metodológicos que permeiam as análises e que devem ser considerados em novas coletas para constituição e ampliação de bancos de dados sociolinguísticos, pois a padronização dos procedimentos metodológicos permite posteriormente a realização de estudos contrastivos entre as variedades, para, então, possibilitar a descrição do 
português brasileiro e estabelecimento de suas normas (FREITAG; MARTINS, TAVARES, 2012; FREITAG, 2014).

Este texto está assim organizado: nas duas seções seguintes apresentamos os resultados obtidos para fenômenos variáveis no português que foram estudados na amostra do VARSUL de Florianópolis e em outras variedades: a expressão da primeira pessoa do plural e a do passado imperfectivo; na seção 4, levantamos a discussão sobre as escolhas metodológicas na constituição de amostras de bancos de dados sociolinguísticos; e na seção 5, passamos às considerações finais.

\section{A PRIMEIRA PESSOA DO PLURAL}

No português falado no Sul do Brasil, estudos (por exemplo, SEARA, 2000; TAMANINE, 2002; BRUSTOLIN, 2009) mostram a implementação da variante $a$ gente. Seara (2000, p. 185) investigou a variação do sujeito nós e a gente na amostra do VARSUL de Florianópolis/SC. Vejamos ocorrências das variantes na amostra investigada, em (1) e (2).

(1) Eu era aprendiz de marinheiro. Eu conheci ela foi no mês de abril ou maio de mil novecentos e quarenta. Aí nós(eu + ela) ficamos correspondendo, coisa e tal. $(\text { Inf.06-591) })^{3}$

(2) Toda vida assim eu e ela, a gente, (eu + minha mãe) toda vida, se deu muito bem mesmo, eu e a mãe, né? (Inf.03-1068)

Foram analisados 733 contextos de primeira pessoa do plural na posição de sujeito, das quais $72 \%$ são de uso da variante $a$ gente. Quanto à faixa etária, o pronome $a$ gente foi mais expressivo na faixa etária jovem, de 15 a 24 anos (com peso relativo de 0,69 ), diminuindo o uso na faixa etária superior a 50 anos (peso relativo de 0,40). Esse resultado, segundo a autora, pode ser um indicativo de que a forma pronominal nós talvez estivesse cedendo lugar para a forma pronominal a gente. Quanto ao fator sexo, os informantes masculinos valeram-se mais do uso da variante nós (peso relativo de 0,70 ), enquanto os femininos tenderam mais ao uso da variante a gente, totalizando $80 \%$ (peso relativo de 0,66 ). No que se refere à escolaridade, os informantes com grau colegial apresentaram maior uso da forma pronominal a gente (peso relativo de 0,56) em relação aos informantes com grau de escolaridade primária (peso relativo de 0,46 ).

O estudo de Tamanine (2002) amplia o escopo da variação na referência à primeira pessoa do plural pelas formas nós e a gente em posição de sujeito para entrevistas do banco do VARSUL das cidades catarinenses de Chapecó (região oeste de Santa Catarina), Blumenau (região nordeste) e Lages (região central). Vejamos a atuação das variantes nas ocorrências (3) e (4).

(3) Aí a gente tem que ficar em cima da ponte, pulo ou não pulo. (BLU SL0806) (TAMANINE, 2002, p. 43)

\footnotetext{
${ }^{3}$ Os códigos ao fim do exemplo referem-se à identificação do informante e sua estratificação social.
} 
(4) Isso era umas sete horas da noite, no outro dia, de manhã, nós chegamos lá na casa para dar uma olhadanão deu nem para entrar. (BLU SL0673) (TAMANINE, 2002, p. 49)

Foram considerados 3.887 contextos de nós e a gente, distribuídos nas entrevistas das três localidades investigadas conforme a Tabela 1.

Tabela 1: Distribuição de nós e a gente nas amostras de Santa Catarina do VARSUL

\begin{tabular}{llll}
\hline & A gente/\% & Nós/\% & TOTAL/\% \\
\hline Lages & $771 / 58$ & $562 / 42$ & $1333 / 34$ \\
Chapecó & $615 / 47$ & $694 / 53$ & $1309 / 34$ \\
Blumenau & $749 / 60$ & $496 / 40$ & $1245 / 32$ \\
TOTAL & $2.135 / 55$ & $1.752 / 45$ & 3887
\end{tabular}

Fonte: Adaptado de Tamanine (2002, p. 120)

Os resultados indicam que a forma a gente tende a suplantar o uso da forma nós como referência à primeira pessoa do plural na fala dos informantes das três localidades investigadas. A cidade representante da formação étnica alemã, Blumenau, mostrou a maior tendência de uso de a gente. Lages, fundada por paulistas, ocupou uma posição intermediária na tendência para o uso da forma nova em relação às outras duas cidades. Por outro lado, Chapecó, constituída por gaúchos descendentes de imigrantes italianos, foi a localidade que apresentou maior tendência para o uso de nós, ou seja, no contexto geral, foi a cidade com os menores índices para o uso de a gente. Chapecó revelou-se como um reduto do uso de nós, principalmente conservado na fala dos homens.

Como a coleta de dados das amostras foi realizada na mesma fatia temporal e seguindo a mesma metodologia de coleta, podemos considerar a variável como uma baliza de fronteira dialetal. Na referência à primeira pessoa do plural, os estudos revelam o caráter crescente do uso da forma a gente na fala e corroboram a crença de que, no Brasil, notadamente no Sul do país, todos falam português, todos se entendem, mas todos estabelecem um julgamento de pertença ou de diferença, que é indiciado pela distribuição de frequências, com a resistência de Chapecó no uso do nós.

\section{PASSADO IMPERFECTIVO}

$\mathrm{O}$ aspecto imperfectivo está relacionado à impossibilidade de se determinar os pontos inicial ou final da situação, com foco voltado ao seu desenvolvimento, em contraponto ao perfectivo, que enfatiza os pontos inicial ou final da situação. $\mathrm{O}$ imperfectivo também é uma característica de um período de tempo que inclui o ponto de referência, como uma situação habitual; é o sentido mais geral e mais abstrato da aspectualidade, em oposição ao sentido mais específico, o progressivo, do qual derivam os demais sentidos, até o imperfectivo genérico, que afrouxa as exigências semânticas para a determinação das nuanças da imperfectividade, e pode recobrir todos os valores aspectuais do imperfectivo. Considerando a oposição específico/genérico, as nuanças da imperfectividade podem ser distribuídas em função de uma trajetória de 
gramaticalização, que pode dar pistas de como se deu a generalização/expansão dos contextos de uso das formas na expressão do passado imperfectivo. O domínio aspectual do imperfectivo pode ser subespecificado em nuanças de imperfectividade, que são definidas em função de dois traços básicos: o intervalo da estrutura temporal e a recorrência da situação, os quais, combinados entre si, possibilitam postular a seguinte trajetória de mudança semântico-discursiva:

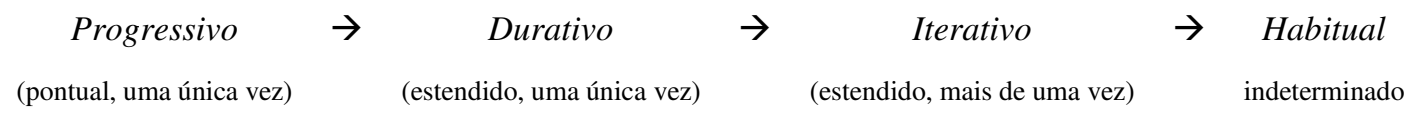

No escopo do tempo passado, em português, duas formas verbais podem expressar os valores semântico-discursivos relacionados à imperfectividade: o pretérito imperfeito (IMP) e a construção perifrástica estar IMP + Vndo (PPROG), como em (5), foco do estudo de Freitag (2007, p. 17), na amostra do VARSUL de Florianópolis/SC.

(5) Depois me aborreci, não era o tipo de serviço que eu estava querendo, aí passei a ser funcionário do Banco Econômico, trabalhava no setor de transporte de malote. (SC FLP MAP 02)

Foram identificados 882 contextos de passado imperfectivo, com 546 ocorrências de IMP (62 \%). Quanto ao valor aspectual expresso, o passado imperfectivo durativo é a função que mais contabiliza ocorrências, com 616 de um total de 882 . Os dados classificados como ambíguos perfazem a segunda maior totalização de ocorrências. A ambiguidade, como apontado anteriormente, é uma consequência do processo de gramaticalização, e a decisão metodológica de controlar os dados ambíguos na análise quantitativa tem como motivação o caráter fluido e contínuo do processo, captando uma instância em que as formas ainda não adquiriram totalmente as características da função-alvo e também não perderam as características da funçãofonte.

Os valores aspectuais progressivo e iterativo mostram-se fortemente correlacionados com uma forma prototípica para sua expressão. $\mathrm{O}$ valor aspectual de passado imperfectivo progressivo está associado à forma PPROG, com peso relativo de 0,83 , ao passo que o valor aspectual de passado imperfectivo iterativo associa-se à forma IMP, com peso relativo de 0,76 . A visualização dos pesos relativos no Gráfico 1 evidencia a correlação entre formas e funções. 


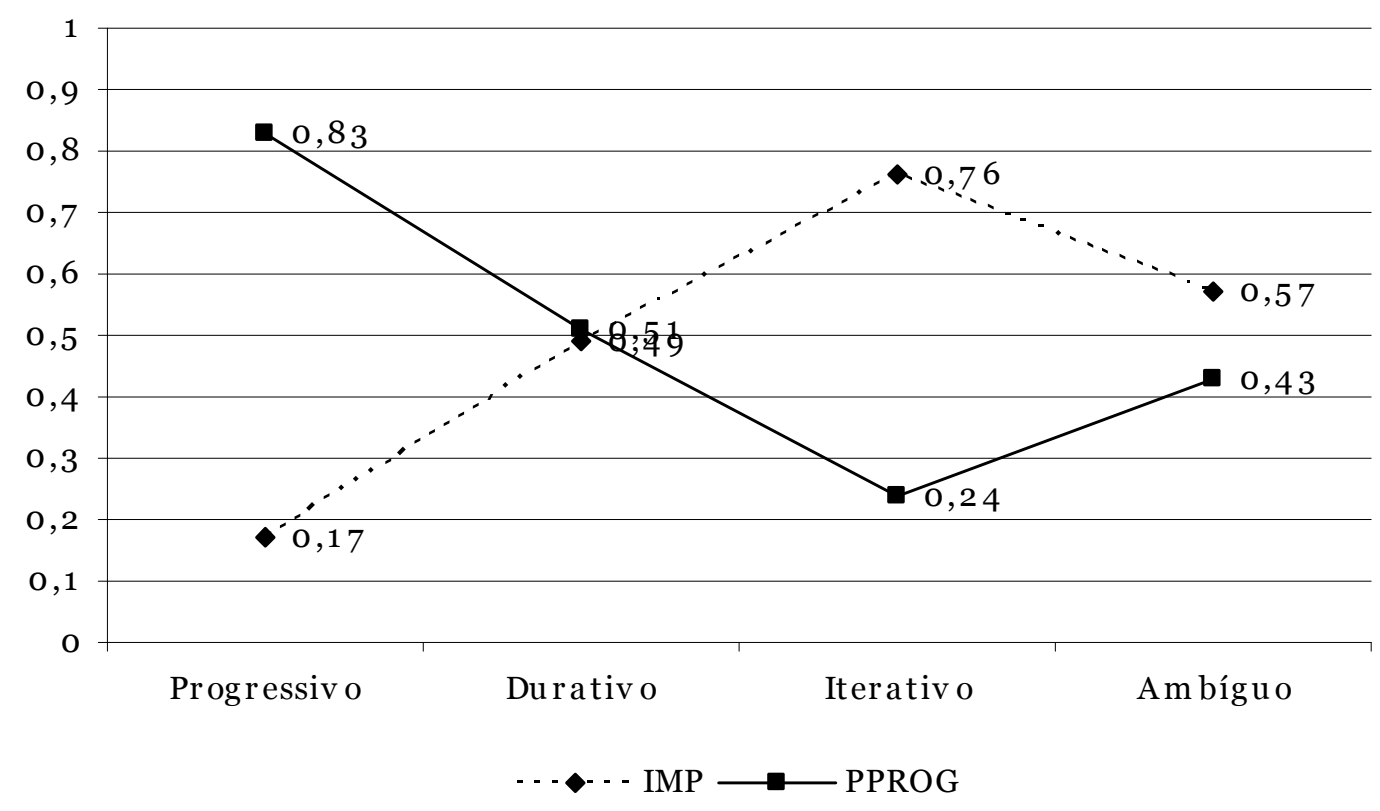

Gráfico 1: Pesos relativos de IMP e PPROG na expressão de passado imperfectivo em função dos valores aspectuais - amostra VARSUL Florianópolis/SC (FREITAG, 2007, p. 137)

A análise da distribuição de frequências das formas IMP/PPROG em 36 entrevistas da amostra de Florianópolis, do Banco de Dados VARSUL, estratificadas quanto ao sexo, três faixas etárias, faixa etária ( 15 a 21 anos, 25 a 49 anos e mais de 50 anos) e o tempo de escolarização ( 2 a 4 anos, 5 a 8 anos e 9 a 11 anos), aponta para uma mudança em função da gradação etária, conforme o Gráfico 2 e corroboram as trajetórias de gramaticalização propostas.

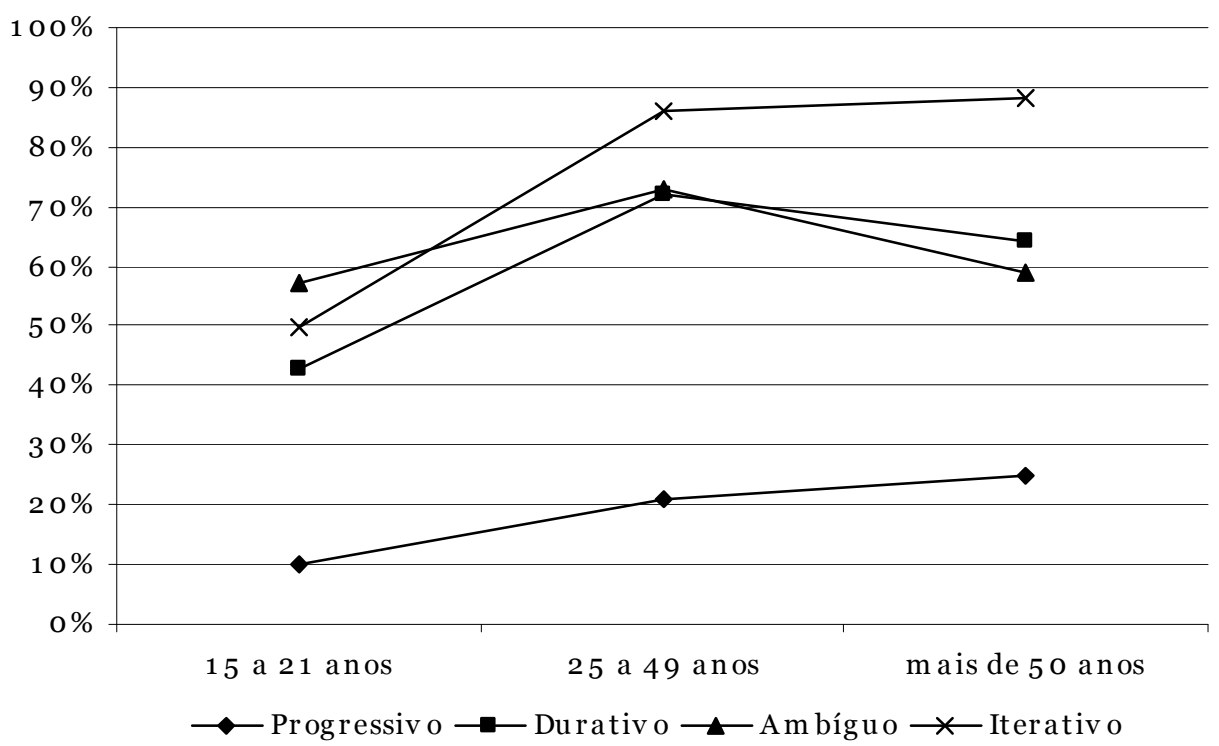

Gráfico 2: Distribuição das frequências de IMP na expressão do passado imperfectivo nas faixas etárias em função do valor aspectual - amostra VARSUL Florianópolis/SC (FREITAG, 2007, p.188). 
A curva delineada em função da faixa etária é ascendente para os valores progressivo e iterativo (o valor habitual é categoricamente associado à IMP na amostra). A curva também pode indiciar qual a forma conservadora e qual a forma inovadora para expressar a função de passado imperfectivo. O uso da forma IMP é fortemente restringido entre os mais jovens, tendo incremento no uso nas faixas etárias mais altas, notadamente na faixa etária acima dos 50 anos. Por outro lado, os resultados apontam que a forma inovadora é PPROG. O valor progressivo - o valor aspectual mais específico do imperfectivo - sinaliza a implementação de PPROG: quanto mais jovens, maior o percentual de uso da variante inovadora. Se replicássemos a análise em outra amostra da mesma comunidade de fala, com intervalo de 20 anos (considerando que a amostra do VARSUL foi coletada no início dos anos 1990), esperaríamos uma sinalização de mudança em curso ou verificaríamos se a variação em questão é efeito de gradação etária (LABOV, 1994).

O que acontece se replicarmos a análise do mesmo fenômeno, em outra amostra diacrônica e diatopicamente distinta? Vejamos o resultado da variação na expressão do passado imperfectivo pelas formas IMP, ilustrado em (6), e PPROG, ilustrado em (7), em uma amostra constituída em 2010 na comunidade de fala de Itabaiana, estado de Sergipe (ARAUJO; FREITAG, 2010, p. 8).

(6) Olhe até ontem ((RISOS)) eu achava que seria um curso... né? que... dá as condições de emprego... só que... quando a gente passa a se deparar... né? com um processo seletivo como está tendo agora a gente vê a quantidade muito grande de pessoas formadas (se ita fpsq 02)

(7) Então... várias coisas vêm à nossa mente né? e a gente só vai tendo... vendo o resultado disso com o passar do tempo... e eu estava até conversando com um colega meu... que ele também estava ensinandoné? como professor contratado. (se ita fpsq 02)

Foram identificados 637 contextos de passado imperfectivo, com 541 ocorrências de IMP (85\%). Quanto ao valor aspectual específico, o iterativo é o que está mais fortemente correlacionado com a forma IMP, com um peso relativo de 0,88 . O aspecto habitual está relacionado ao IMP, com peso relativo de 0,79 . Já o contínuo e o progressivo são associados à variante PPROG, com pesos relativos de 0,66 e 0,63, respectivamente. 


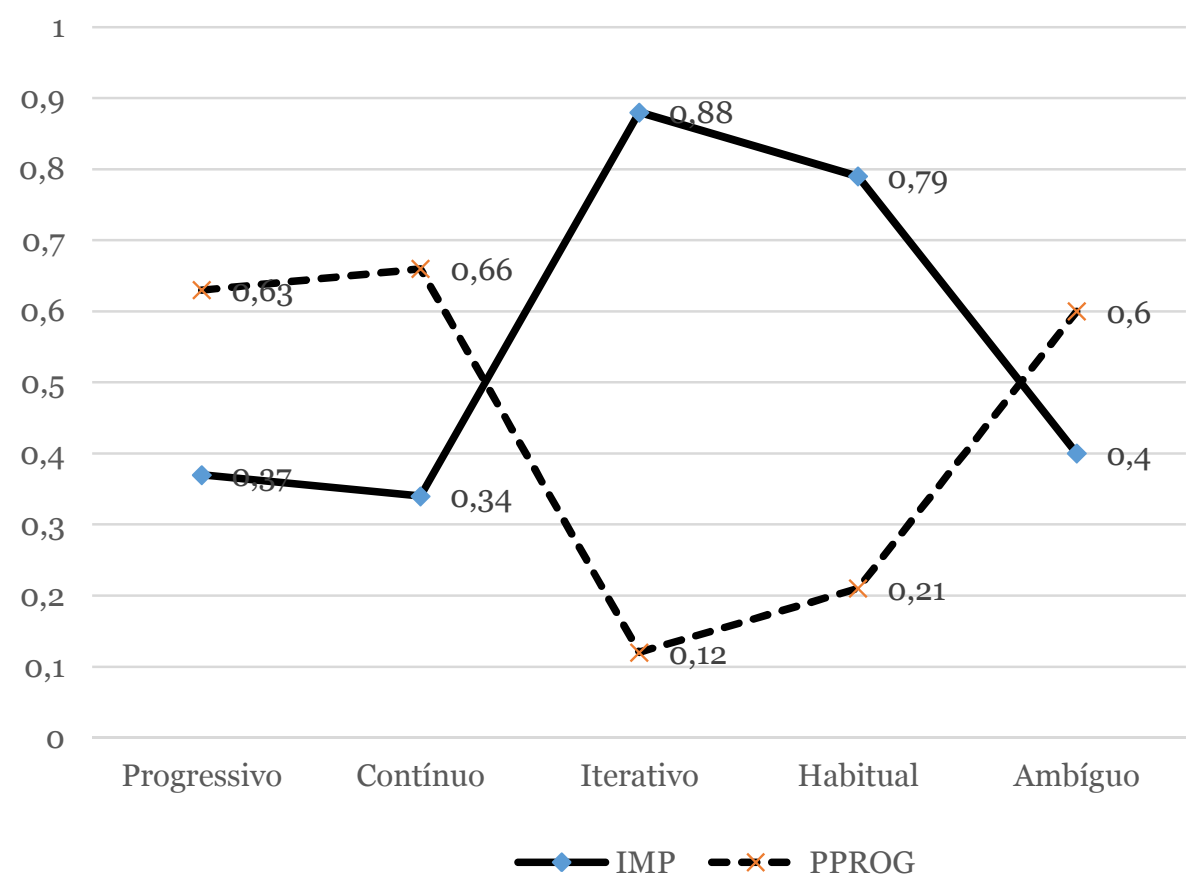

Gráfico 3: Distribuição das frequências de IMP na expressão do passado imperfectivo nas faixas etárias em função do valor aspectual - amostra Falares Sergipanos Itabaiana/SE (adaptado de ARAUJO; FREITAG, 2010, p. 15)

A amostra analisada foi constituída por doze entrevistas sociolinguísticas realizadas com estudantes universitários da unidade de Itabaiana da Universidade Federal de Sergipe, estratificados quanto ao sexo, todos na faixa etária de 21 a 30 anos; e por dezesseis entrevistas sociolinguísticas realizadas com estudantes da educação básica e ensino médio ( $6^{\circ}$ ano da educação básica, $9^{\circ}$ ano da educação básica, $1^{\circ}$ ano do ensino médio e $3^{\circ}$ ano do ensino médio) e estratificadas quanto ao sexo, compreendendo a faixa etária de 12 a 17 anos. O controle da gradação de faixa etária e de escolarização não se mostrou estatisticamente significativo, com distribuição uniforme de ambas as variantes.

No entanto, se compararmos os resultados obtidos na amostra de Itabaiana/SE com as tendências de uso das formas em relação às funções na análise da comunidade de Florianópolis/SC, diacrônica e diatopicamente diferentes, observamos paralelismo de resultados - mais resultados de fatores internos, como o traço semântico-discursivo do verbo e o aspecto lexical também seguem a mesma tendência em ambas as comunidades (cf. ARAUJO; FREITAG, 2010) -, o que pode sugerir que não são motivações externas que influenciam a variação entres as formas, mais sim motivações internas, ou melhor, de natureza semântico-cognitiva, que são estáveis nas diferentes comunidades de fala.

\section{QUESTÕES METODOLÓGICAS}

Se olharmos apenas para os resultados retrospectados nas duas seções anteriores, sem considerações acerca das escolhas metodológicas da constituição das amostras orais, podemos concluir que há diferença entre Florianópolis e Chapecó, em Santa Catarina, no que tange ao uso da primeira pessoa do plural, e que há estabilidade entre 
Florianópolis/SC e Itabaiana/SE - amostras geograficamente opostas -no que refere à expressão do passado imperfectivo.

Considerando a metodologia de coleta, as amostras orais de Chapecó e Florianópolis foram constituídas sob o mesmo protocolo, o do projeto VARSUL, e na mesma época, em meados da década de 1990. A amostra constituída subsidia o constructo do tempo aparente, com a observação da estratificação etária em uma dada sincronia da língua, a partir da qual se delineia a deriva. Para verificar em tempo real a deriva do fenômeno, seria necessário realizar um estudo de painel - com o recontato dos mesmos indivíduos em outra fatia temporal - ou um estudo de tendência - com a constituição de nova amostra compatível e representativa do mesmo perfil sociodemográfico do da amostra da fatia temporal anterior. Atualmente, o banco de dados do VARSUL de Florianópolis está sendo expandido com a coleta da Amostra do Interior de Florianópolis, contemplando zonas urbanas e não urbanas. $\mathrm{O}$ recontato não é uma opção, tampouco a constituição de nova amostra representativa da anterior.

Para Chapecó está em curso o projeto Variação e Mudança Linguística no Português do Oeste de Santa Catarina ${ }^{4}$, que visa à constituição de uma amostra da fala de 32 informantes, monolíngues em português. O foco da coleta são informantes das faixas etárias de 7 a 14 anos e 15 a 24 anos, não contempladas na amostra de Chapecó do VARSUL. Mais uma vez, o estudo de painel, ou mesmo o estudo de tendência, não foi a prioridade. Ao optar por priorizar a faixa etária jovem, o projeto parte da premissa laboviana de mudança de que as diferenças linguísticas entre gerações podem espelhar desenvolvimentos diacrônicos, quando outros fatores se mantêm constantes (LABOV, 1994). Além disso, como o comportamento linguístico de cada geração reflete um estágio de língua, os grupos etários mais jovens podem introduzir novas alternantes que, gradativamente, substituirão aquelas que caracterizam o desempenho linguístico dos falantes de faixas etárias mais avançadas. Ao invés de priorizar o recontato ou a constituição de nova amostra compatível e representativa da do VARSUL de Chapecó (e a priorização decorre de imperativos financeiros interpostos), o projeto prioriza a fase da vida linguística do indivíduo em que se dá a fixação do sistema linguístico e que é sensível às redes sociais e traços identitários de grupo, mais afeita aos estudos de $3^{\text {a }}$ onda da sociolinguística (FREITAG; MARTINS; TAVARES, 2012).

A amostra de entrevistas sociolinguísticas do banco de dados Falares Sergipanos $^{5}$ é constituída por informantes universitários na faixa etária de 21 a 30 anos. A opção por uma única faixa de escolarização e uma única faixa etária decorre do objetivo dos estudos vinculados ao banco de dados, que visa o contraste com comunidades de práticas, em coletas de base interacional, distanciando-se do modelo laboviano, a fim de verificar efeitos da coleta de dados nos resultados, com o controle de fatores de ordem pragmática. O perfil social da amostra é compatível com um dos perfis sociais da amostra do projeto Variação e Mudança Linguística no Português do Oeste de Santa Catarina e com o perfil da ampliação da amostra do VARSUL de Florianópolis que incorpora informantes com nível superior; uma análise do fenômeno de variação na expressão do passado imperfectivo nessas duas amostras pode referendar

\footnotetext{
${ }^{4}$ Financiado com recursos da Chamada Pública FAPESC 04/2012 Universal. Aprovado pelo Comitê de Ética em Pesquisa da Universidade Federal da Fronteira Sul (Processo CAAE: 17011413.2.0000.5564).

${ }^{5}$ O projeto Falares Sergipanos, detalhado em Freitag (2013), integra um projeto maior, intitulado $D a$ expressividade da língua ao mal na literatura: base de pesquisas interinstitucionais do PPGL/UFS, financiado pelo edital CAPES/FAPITEC/SE 06/2012. Aprovado pelo Comitê de Ética em Pesquisa da Universidade Federal de Sergipe (Processo CAAE: 0386.0.107.000-11).
} 
a deriva de que o fenômeno é estável diatópica e diatrasticamente, motivado por fatores de ordem semântico-cognitiva.

Devemos lembrar que a metodologia da Sociolinguística variacionista é pautada em critérios visando a confiabilidade - os mesmos resultados devem ser repetidos na análise do mesmo fenômeno - e intersubjetividade - dois pesquisadores diferentes devem obter os mesmos resultados seguindo a mesma metodologia - das análises (BAILEY; TILLERY, 2004), de modo a possibilitar a generalização de resultados. Enquanto descrições de base dialetológica, a exemplo do Atlas Linguístico do Brasil ALIB têm conseguido manter um protocolo padrão em suas diferentes amostras, as descrições de base sociolinguística variacionista não têm um padrão "nacional", e dificilmente terão; a configuração dos perfis sociais da amostra sociolinguística é sensível aos traços identitários locais, o que não permite que se siga um padrão prédefinido.

Constituir bancos de dados linguísticos, seja nos moldes variacionistas, geolinguísticos ou diacrônicos, costuma ser tarefa cara e dispendiosa, por isso, sua aplicação precisa ser otimizada, subsidiando a pesquisa de diversos fenômenos de variação linguística, tanto na dimensão social como também na dimensão estilística. Mais do que constituir novos bancos de dados, é necessário dar continuidade à obtenção de amostras de bancos de dados sociolinguísticos já constituídos, visando manter a série histórica, para permitir captar tendências amplas de variação/mudança. No entendimento de Labov (1994, p. 63), "esta combinação de observações no tempo aparente e no tempo real é o método básico para o estudo da mudança em progresso." $\mathrm{Na}$ formação de novos bancos de dados, é desejável seguir uma metodologia já convencionalizada e difundida, o que permite a comparação de resultados. No entanto, é preciso também incorporar novas categorias sociodemográficas nas estratificações de bancos de dados sociolinguísticos e revisão das já existentes, a fim de acompanhar a dinâmica da sociedade e captar os perfis identitários locais de cada comunidade de fala.

\section{CONSIDERAÇÕES FINAIS}

A amostra de Florianópolis do VARSUL não só tem subsidiado estudos de fenômenos variáveis do português brasileiro, mas também tem sido a base para a replicação de outros bancos de dados, como o Falares Sergipanos e o Variação e Mudança Linguística no Português do Oeste de Santa Catarina, cujas coordenadoras valeram-se da experiência de pesquisa na amostra em seus trabalhos de mestrado e doutorado (ROST, 2002; ROST SNICHELLOTO, 2009; FREITAG, 2003; 2007). Face a novas realidades sociolinguísticas e institucionais, surgem novos bancos de dados não necessariamente em decalque ao modelo (assim como o VARSUL difere-se do PEUL), mas com pontos de aderência que permitem as análises contrastivas.

A emergência desses novos bancos de dados só vem ressaltar a fama de que o VARSUL de Florianópolis tem atuado significativamente na formação de novos pesquisadores na área daSociolinguística, colaborando para a expansão dos estudos descritivos do português brasileiro. Somos gratas pela oportunidade que nos foi dada pela equipe VARSUL de Florianópolis! 


\section{REFERÊNCIAS}

ABRAÇADO J.; RONCARATI, C. Português brasileiro - contato linguístico, heterogeneidade e história. Rio Janeiro: 7Letras, 2003.

ABRAÇADO J.; RONCARATI, C. Português Brasileiro II: contato linguístico, heterogeneidade e história. Niterói: EdUFF, 2008.

ARAUJO, A. S.; FREITAG, R. M. K. Variação na expressão do tempo verbal passado na fala e escrita de Itabaiana/SE: formas de pretérito imperfeito e perífrase na expressão do passado em curso. Scientia Plena 6 (1), p. 125801-19, 2010.

ARDUIN, J. A Variação do uso dos pronomes possessivos teu/seu na região sul do Brasil. Florianópolis: UFSC, 2005. [Dissertação de Mestrado em Linguística].

BAILEY, G.; TILLERY, J. Some sources of divergent data in Sociolinguistics. In: FOUGHT, C. Sociolinguistic Variation: Critical Reflections. New York: Oxford University, 2004. p. 11-30.

BRUSTOLIN, A. K. B. S. Itinerário do uso e variação de nós e a gente em textos escritos e orais de alunos do ensino fundamental da rede pública de Florianópolis. Florianópolis: UFSC, 2009. [Dissertação de Mestrado em Linguística].

DAL MAGO, D. QUER DIZER: percurso de mudança via gramaticalização e discursivização. Florianópolis: UFSC, 2001. [Dissertação de Mestrado em Linguística].

FREITAG, R. M. K. A expressão do passado imperfectivo no português: variação/gramaticalização e mudança. Florianópolis: UFSC, 2007. [Tese de Doutorado em Linguística].

FREITAG, R. M. K. Marcadores discursivos não são vícios de linguagem. Interdisciplinar: Revista de Estudos em Língua e Literatura, 4 (4), p. 22-43, 2007.

FREITAG, R. M. K. Marcadores discursivos interacionais na fala de Itabaiana/SE. Revista do GELNE, 10 (1), p. 21-32, 2008.

FREITAG, R. M. K.Banco de dados Falares Sergipanos. WorkingPapers em Linguística, 14(2), p. 156-164, 2013. http://dx.doi.org/10.5007/1984$\underline{8420.2013 v 14 n 2 p 156}$

FREITAG, R. M. K. Metodologia de coleta e manipulação de dados em sociolinguística. São Paulo: Blucher, 2014.

FREITAG, R. M. K. Variação e gramaticalização e de acho (que) e parece (que) na fala de Florianópolis. Florianópolis: UFSC, 2003. [Dissertação de Mestrado em Linguística].

FREITAG, R. M. K.; MARTINS, M. A.; TAVARES, M. A. Bancos de dados sociolinguísticos do português brasileiro e os estudos de terceira onda: potencialidades e limitações. Alfa, 56 (3): p. 917-944, 2012. http://dx.doi.org/10.1590/S1981$\underline{57942012000300009}$

LABOV, W. Principles of linguistic change: internal factors. Oxford: Blackwell, 1994.

MARTINS, L. T. Bom e bem e suas multifunções na fala da Região Sul do Brasil.

Florianópolis: UFSC, 2003. [Dissertação de Mestrado em Linguística].

ROST, C. A. Olha e veja: multifuncionalidade e variação. Florianópolis: UFSC, 2002.

[Dissertação de Mestrado em Linguística]. 
ROST SNICHELOTTO, C. A. Olha e vê: caminhos que se entrecruzam. Florianópolis: UFSC, 2009. [Tese de Doutorado em Linguística].

SEARA, I. C. A variação do sujeito nós e a gente na fala florianopolitana. Organon, 14 (28-29), p.179-194, 2000.

TAMANINE, A. M. B. A alternância de nós/a gente no interior de Santa Catarina. Curitiba: UFPR, 2002. [Dissertação de Mestrado em Estudos Linguísticos].

TAVARES, M. A. Conectores coordenativos: condicionamentos sociais em duas comunidades de fala brasileira. Linguística 4 (1), p. 19-37, 2008.

WIEDEMER, M. L. A regência variável do verbo ir de movimento na fala de Santa Catarina. Florianópolis: UFSC, 2008. [Dissertação de Mestrado em Linguística].

Data de submissão: 18/05/2014

Data de aceite: 11/11/2014 